\title{
Economic and Ecologic Evaluation of Low Temperature Waste Heat Integration Into Existing District Heating
}

\author{
Dominik Hering $^{1}$, André Xhonneux ${ }^{1}$, Dirk Müller ${ }^{1,2}$ \\ ${ }^{1}$ Forschungszentrum Jülich GmbH, Institute of Energy and Climate Research, \\ Energy Systems Engineering (IEK-10), Jülich, Germany \\ ${ }^{2}$ RWTH Aachen University, E.ON Energy Research Center, Institute for Energy Efficient \\ Buildings and Indoor Climate, Aachen, Germany
}

\begin{abstract}
The integration of waste heat into district heating offers the potential to decrease the environmental impact of the district heating's energy supply. A significant amount of waste heat is available at low temperatures, compared to existing district heating networks. In this paper, we generate a simulation model of a district heating network from a database and evaluate the integration of waste heat compared to the original design. Our simulation demonstrates the feasibility of integrating low temperature waste heat into an existing network. The waste heat utilization can decrease the primary energy consumption and $\mathrm{CO}_{2}$ emissions for the respective buildings. These results can be improved further by optimizing the low-temperature network connection of each building.
\end{abstract}

\section{Introduction}

Recent research on district heating focuses on $4^{\text {th }}$ generation district heating systems, which features low flow temperatures in the range of $30{ }^{\circ} \mathrm{C}-70^{\circ} \mathrm{C}$ (Lund et al. (2014)). Low flow temperatures allow new heat sources to be integrated into district heating networks as heat supplies. For example, waste heat from information technology, such as high performance computers (HPC) or data centers can be used as a heat supply for flow temperatures up to $50{ }^{\circ} \mathrm{C}$ (Wahlroos et al. (2017)). The information technology sector consumed between $1.1 \%$ and $1.5 \%$ of global electricity in 2010, with a tendency for more (Koomey (2011)).

Contrarily to the high electricity consumption of the information technology sector, the building sector in Germany is dominated by fossil fuel consumption for room heating. In 2016, $69 \%$ of energy consumption of private households was used for room heating (Umweltbundesamt (2018a)) and 60\% of energy consumption was supplied by fossil fuels (Umweltbundesamt (2017)). Thus, integrating waste heat from information technology sources into district heating networks has the potential to decrease the overall energy consumption.

For new district heating networks, this integration can be part of the planning phase and a distribu- tion network and building energy systems can be designed accordingly. However, in Germany and other countries a large part of building energy systems and district heating infrastructure already exists. Especially building energy systems vary between multiple standards of insulation and heating and are thus often unfit for low temperatures. Additionally, existing district heating networks are designed as hightemperature district heating, often operating with flow temperatures of more than $100^{\circ} \mathrm{C}$ (Lund et al. (2014)).

\section{Case study}

In the course of the Living Lab Energy Campus project (LLEC), the district heating network of Forschungszentrum Jülich (FZJ) campus is investigated. The campus consists of more than 100 consumers with a combined peak load exceeding $25 \mathrm{MW}$. Additionally, FZJ campus houses an HPC cluster. This cluster contains, among others, one system with liquid water cooling, which results in cooling temperatures of up to $40^{\circ} \mathrm{C}$. We are going to use this waste heat to heat the surrounding buildings. The existing district heating network was built in the 1950s and can be classified as a $2^{\text {nd }}$ generation district heating network according to Lund et al. (2014)). The supply of the district heating network becomes refurbished and a natural gas fired Combined Heat and Power (CHP) plant will supply the district heating network. The heat carrier in the district heating network is pressurized hot water. The flow temperature depends on the ambient air temperature and ranges between $95^{\circ} \mathrm{C}$ and $132^{\circ} \mathrm{C}$ with a design return temperature of $60^{\circ} \mathrm{C}$. The CHP plant can supply up to $13.5 \mathrm{MW}$ at $115^{\circ} \mathrm{C}$. Additional heat is supplied by a gas burner. The pipe network is realized as a meshed network to guarantee a high security of supply. The topology of the network is stored in a geographic information system in a citygml database with EnergyADE expansion (Fuchs et al. (2016)).

The HPC systems on the FZJ campus operate with a waste heat temperature between $30^{\circ} \mathrm{C}$ and $40^{\circ} \mathrm{C}$. The integration of waste heat into an existing net- 
work is feasible in multiple ways.

One option is to supply waste heat into the return flow of the existing network. In the existing network the return temperature is $60^{\circ} \mathrm{C}$. This return temperature is $20 \mathrm{~K}$ higher than the expected flow temperature of the HPC waste heat. Thus, the integration of waste heat into the existing network seems unfavorable. Furthermore, the available thermal power of HPC waste heat sums up to $1.5 \mathrm{MW}$ and therefore cannot supply the whole campus. Instead, we separate a network around the HPC from the high-temperature network and transform it to a low-temperature network.

The buildings in the surroundings of the HPC are built between 1967 and 2020 and have different use conditions, ranging from office over laboratory to cafeteria. The design flow temperature of the building energy systems is $70^{\circ} \mathrm{C}$ and the design return temperature is $55^{\circ} \mathrm{C}$.

\section{Methods}

For this study, we generate dynamic simulation models of district heating networks. Therefore, the model generation is discussed briefly, followed by an overview over the evaluation functions. For the evaluation, we compare the existing high-temperature network to the new low-temperature network. This results in three network scenarios.

First, in the $\mathrm{LTDH}_{\mathrm{HX}}$ scenario, we simulate the low temperature network with retrofitted building energy systems. This comprises exchanging every radiator and every air handling unit to work with the lowtemperature network. The building is connected to the low-temperature network by a heat exchanger.

Second, for the $\mathrm{LTDH}_{\mathrm{HP}}$ scenario, we simulate a heat pump in every building. In this scenario, no radiator or air handling unit of the building energy system needs to be changed. Therefore, the building energy system operation temperatures remain unchanged. Instead, a heat pump connects the building energy system to the low-temperature network.

Third, the HTDH scenario represents the reference status of the high-temperature network. It consists of a CHP supply and all buildings on the campus are connected by heat exchangers. The number of buildings supplied by the HTDH scenario is higher compared to the LTDH scenarios, because the whole campus is connected to this network. We want to determine the effect of the buildings in the low-temperature scenarios by creating two hightemperature simulation models. The $\mathrm{HTDH}_{\text {ref }}$ model contains all buildings of the campus. The $\mathrm{HTDH}_{\text {new }}$ scenario contains all buildings of the campus without the buildings connected to the low-temperature network.

\section{Simulation model}

The data for the simulation model is derived from a citygml database. The database contains spatial coordinates of the high-temperature network, as well as building information. Data used for pipe network generation consists of geographic information system coordinates of pipes, the length of each pipe and the inner diameter of each pipe. Figure 1 shows the graph of the high-temperature network.

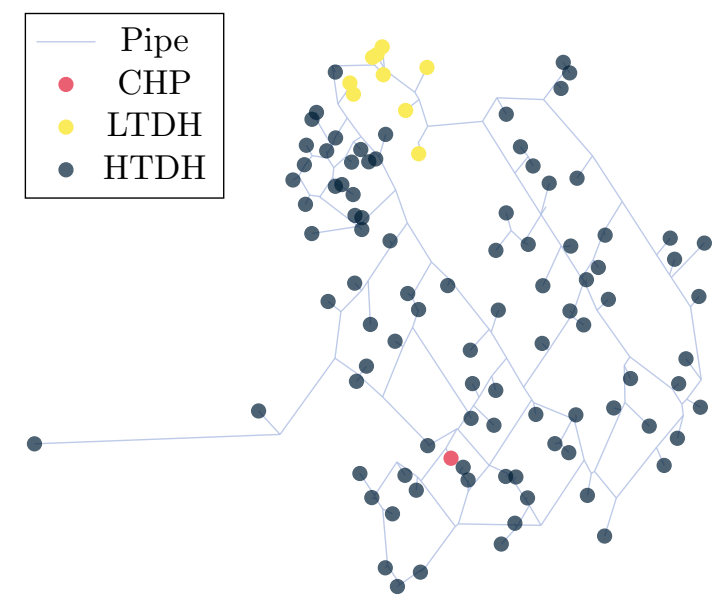

Figure 1: Graph for the high-temperature scenario

The pipe network shown in Figure 1 is generated with the open source Python package uesgraphs (Fuchs et al. (2016)). This package reads the network information from the citygml database and creates a structured graph.

For the LTDH simulation models we separate the yellow demand nodes of Figure 1 from the hightemperature network. The resulting low-temperature network is shown in figure 2 .

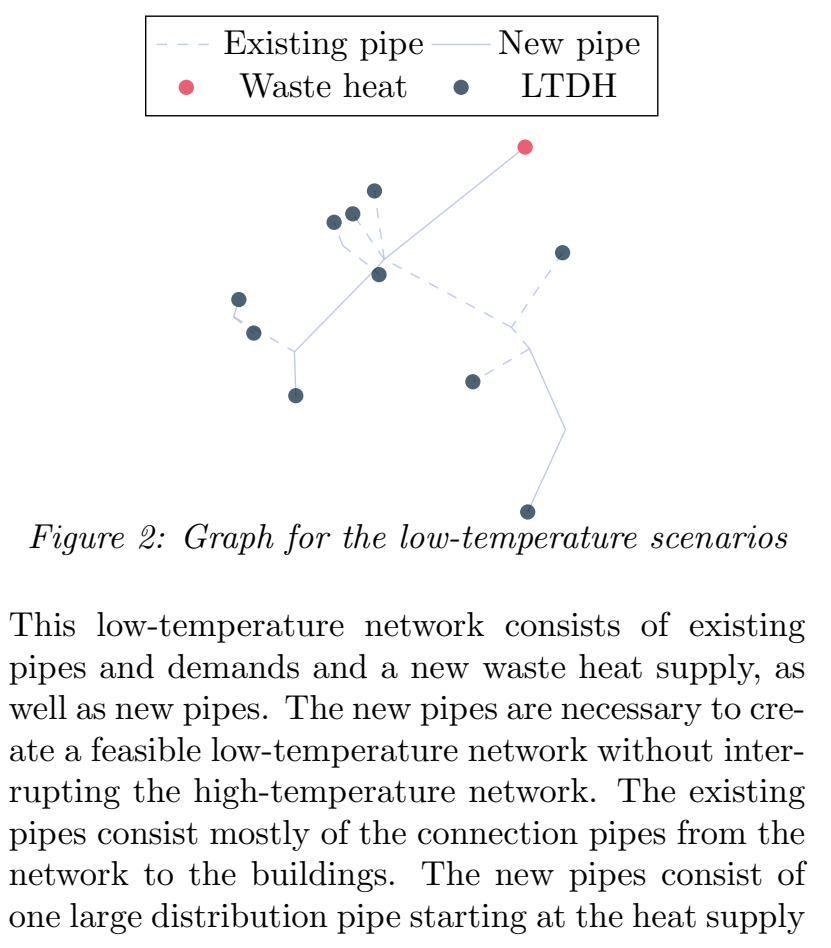


and one additional connection pipe to a remote building. We create a simulation model from the network graph using the Python package uesmodels (Fuchs et al. (2016)). This package reads the information of the uesgraph instance and creates a Modelica model. This model uses supply, demand and pipe models of the open source Modelica library AixLib (Müller et al. (2016)). We simulate the supply as an ideal supply as shown in figure 3 .

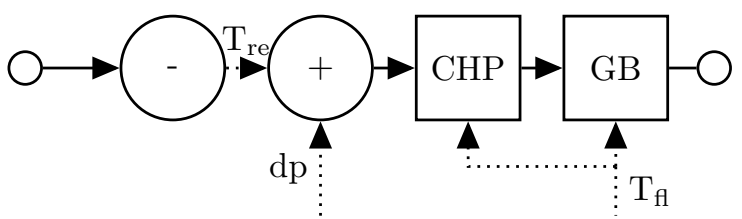

Figure 3: Diagram of ideal supply model

The supply consists of a fluid source, a fluid sink and the two heat sources CHP and gas burner (GB). The flow pressure is controlled by a PI-controller. This controller holds the differential pressure at the farthermost building constant. The flow temperature setpoint, $\mathrm{T}_{\mathrm{fl}}$, is based on the measured flow temperature of the high-temperature network supply. The water is supplied by the source with the return Temperature $\mathrm{T}_{\mathrm{fl}}$ and first flows through the CHP. If the power or maximum temperature of the CHP is not sufficient for the demand, the gas burner supplies the additional power.

As demands, we use two different models. For the $\mathrm{LTDH}_{\mathrm{HP}}$ simulation, we use a heat pump demand model. The function of the heat pump demand model is shown in figure 4 .

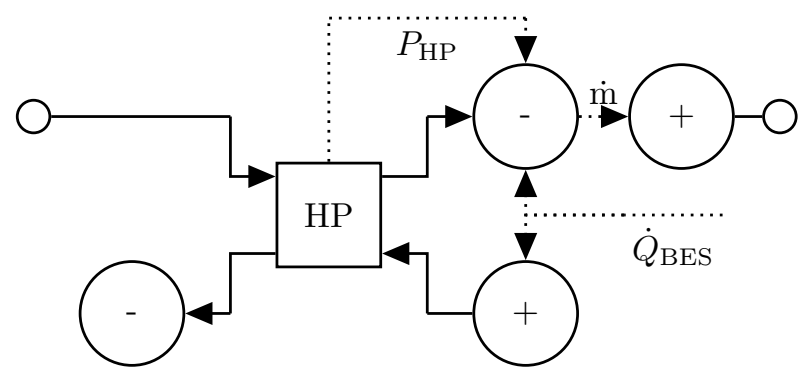

Figure 4: Diagram of heat pump demand model

The mass flow rate on the building energy system site depends on the demand of the building, $\dot{Q}_{\text {BES }}$. The mass flow rate of the network depends on $\dot{Q}_{\mathrm{BES}}$ and on the power of the heat pump, $P_{\mathrm{HP}}$. For the models $\mathrm{LTDH}_{\mathrm{HX}}, \mathrm{HTDH}_{\text {ref }}$ and $\mathrm{HTDH}_{\text {new }}$ we use a simple demand model which simulates a heat exchanger substation. The difference of the simple demand model to the model shown in figure 4 is the lack of a heat pump component. Instead, the mass flow rate of the network directly depends on $\dot{Q}_{\mathrm{BES}}$.

The pipe model is based on the IBPSA plug flow pipe model and simulates pressure drop and thermal losses (van der Heijde et al. (2017)). We add information about pipe insulation and wall roughness in Python according to manufacturer data. Furthermore, we use the parameter fac of the pipe model to simulate additional pressure losses due to fittings and bends in the pipe network. We calculate $f a c$ according to the equivalent length method (Coker and Ludwig (2007)) shown in equation 1.

$$
f a c=1+\frac{d}{l} \cdot \sum(l / d)_{\mathrm{eq}}
$$

$\sum(l / d)_{e q}$ adds up additional pressure losses caused by fittings and bends (Coker and Ludwig (2007)). We set this value based on information about additional pressure losses in the existing high-temperature network. For all scenarios we set the demand data equal to the measured consumption data of 2017. We use a time resolution of $900 \mathrm{~s}$ for all simulations.

\section{Evaluation function}

For the evaluation of the scenarios, we use the simulation results and compare them using five parameters. First, we check the pressure drop of every pipe during the simulation. Second, we conduct an exergy analysis, as well as a primary energy and a $\mathrm{CO}_{2}$ emission balance. Third, we compare the results economically with a net present value analysis.

\section{Pressure drop}

First, we investigate the pressure drop of every pipe. Due to the small temperature difference of $10 \mathrm{~K}$ in the low-temperature network compared to $60 \mathrm{~K}$ in the high-temperature network, the mass flow rate in existing pipes will increases. Thus, mass flow limits, and subsequently pressure drop in the low-temperature network can exceed pipe capacities. To evaluate feasible pipe operation, we plot the maximal mass flow rate and pressure drop of every pipe in a pressure drop chart.

\section{Exergy}

Second, we conduct an exergy analysis. Equation 2 describes the total thermal exergy consumption.

$$
E x=E x_{\mathrm{el}}+E x_{\mathrm{wh}}+E x_{\mathrm{ng}}
$$

The total exergy consumption, $E x$, consists of three summands, the exergy of electrical energy, $E x_{\mathrm{el}}$, for heat pump and circulation pump operation in the district heating network, the exergy of HPC waste heat, $E x_{\mathrm{wh}}$, and the exergy of natural gas, $E x_{\mathrm{ng}}$, for the CHP and gas burner operation.

Electrical energy flow equals electrical exergy flow, and natural gas energy flow equals natural gas exergy input. Thermal exergy flow is calculated from thermal energy flow $\dot{Q}_{\text {wh }}$ according to equation 3 .

$$
E x_{\mathrm{wh}}=\int_{0}^{1 \mathrm{a}} \dot{Q}_{\mathrm{wh}}(t) \cdot\left(1-\frac{T_{\mathrm{BES}}}{T_{\mathrm{wh}}}\right) \mathrm{d} t
$$

$\dot{Q}_{\text {wh }}$ is the thermal power of waste heat with the corresponding flow temperature $T_{\mathrm{wh}}$. $T_{\mathrm{BES}}$ is the reference temperature and equals the room temperature 
of $20^{\circ} \mathrm{C}$. For both low-temperature scenarios no natural gas is required and therefore $E x_{n g}$ is set to 0 . Thus, the exergy consumption of electric energy and thermal waste heat energy flows need to be calculated. $E x_{e l}$ is the sum of pump and heat pump operation power. Therefore, we calculate the pump energy, $E_{\text {pump }}$ from the simulation result with equation 4 .

$$
E_{\text {Pump }}=\int_{0}^{1 \mathrm{a}} \frac{\dot{m}_{\text {Supply }}(t) \cdot \Delta p_{\text {Supply }}(t)}{\rho_{\text {Water }} \cdot \eta_{\text {Pump }}} \mathrm{d} t
$$

We assume a constant efficiency of $80 \%$ for the pump. The electric energy consumption of the heat pump model, $E_{\mathrm{HP}}$, is taken from the simulation results.

We want to compare the low-temperature scenarios with the high-temperature scenario. However, the $\mathrm{HTDH}_{\text {ref }}$ model simulates a larger number of buildings compared to the low-temperature scenarios. Thus, we can not compare them directly. Instead, we simulate the $\mathrm{HTDH}_{\text {ref }}$ model and the $\mathrm{HTDH}_{\text {new }}$ model and use both results to calculate the demand of the low-temperature buildings. For those calculations, we use simulated values at the supply station. Therefore, the demand data accounts for changes in thermal losses of the network, as well as changes in pump energy consumption. We calculate this difference with equation 5 .

$$
\Delta E_{\mathrm{CHP}}=\int_{0}^{1 \mathrm{a}}\left[\dot{Q}_{\mathrm{CHP}, \mathrm{ref}}(t)-\dot{Q}_{\mathrm{CHP}, \text { new }}(t)\right] \mathrm{d} t
$$

$\Delta E_{\mathrm{CHP}}$ is the difference of thermal energy supplied by the CHP plant to the high-temperature network. The difference in natural gas consumption is calculated with equation 6 .

$$
\Delta E x_{\mathrm{ng}}=\frac{\Delta E_{\mathrm{CHP}} \cdot(1+\sigma)}{\omega}+\Delta E_{\mathrm{GB}}
$$

We set the power to heat ratio, $\sigma$, to 1 and the fuel utilization ratio, $\omega$, to $90 \% . \Delta E_{\mathrm{GB}}$ is the difference in thermal energy supplied by the gas burner and is calculated similar to $\Delta E_{\mathrm{CHP}}$. The CHP plant is operated heat driven and generates electricity as a byproduct. The generated electrical exergy, $E x_{\mathrm{el}, \mathrm{CHP}}$, is calculated with equation 7 .

$$
\Delta E x_{\mathrm{el}, \mathrm{CHP}}=\Delta E_{\mathrm{CHP}} \cdot \sigma
$$

Overall, the consumed exergy is calculated with equation 8 for the $\mathrm{LTDH}_{\mathrm{HX}}$ scenario, with equation 9 for the $\mathrm{LTDH}_{\mathrm{HP}}$ scenario and with equation 10 for the HTDH scenario.

$$
\begin{gathered}
E x_{\mathrm{LTDH}, \mathrm{HX}}=E x_{\mathrm{el}, \mathrm{Pump}}+E x_{\mathrm{wh}} \\
E x_{\mathrm{LTDH}, \mathrm{HP}}=E x_{\mathrm{el,Pump}}+E x_{\mathrm{wh}}+E x_{\mathrm{el}, \mathrm{HP}}
\end{gathered}
$$

\section{Primary energy}

Third, the primary energy consumption of both low-temperature scenarios is compared to the hightemperature scenario. We compare all energy flows using the primary energy factors $\left(f_{\mathrm{P}}\right)$ for Germany (Der Energieeffizienzverband für Wärme, Kälte und KWK e.V. (2014)). Table 1 shows the primary energy factors used for the primary energy balance.

Table 1: Primary energy factors

\begin{tabular}{lll}
\hline Energy & $f_{\mathrm{P}}$ & Symbol \\
\hline Electricity & 2.8 & $f_{\mathrm{P}, \mathrm{el}}$ \\
Non renewable electricity & 1.8 & $f_{\mathrm{nreP}, \mathrm{el}}$ \\
Natural gas & 1.1 & $f_{\mathrm{P}, \mathrm{ng}}$ \\
\hline
\end{tabular}

The primary energy consumption of each scenario is calculated with equation 11 .

$$
P E=E_{\mathrm{el}} \cdot f_{\mathrm{nreP}, \mathrm{el}}+\Delta E_{\mathrm{ng}} \cdot f_{\mathrm{P}, \mathrm{ng}}-\Delta E_{\mathrm{CHP}, \mathrm{el}} \cdot f_{\mathrm{P}, \mathrm{el}}
$$

For the primary energy balance, we use three energy balances according to the source of energy listed in table 1 . The values for $E_{\mathrm{el}}, \Delta E_{\mathrm{ng}}$ and $\Delta E_{\mathrm{CHP}, \mathrm{el}}$ are already calculated for the exergy balance.

\section{$\mathrm{CO}_{2}$ emissions}

Fourth, we compare the $\mathrm{CO}_{2}$ emissions of all scenarios. For this comparison, we calculate electrical energy and natural gas consumption from simulation results. The $\mathrm{CO}_{2}$ emissions are calculated using $\mathrm{CO}_{2}$ emission factors $\left(f_{\mathrm{CO}_{2}}\right)$ according to the Umweltbundesamt (2018b). Table 2 shows the $\mathrm{CO}_{2}$ emission factors for Germany in 2017.

\begin{tabular}{lll} 
Table 2: $\mathrm{CO}_{2}$ & emission factors $[\mathrm{kg} / \mathrm{kWh}$ \\
\hline Energy & $\mathrm{CF}$ & Symbol \\
\hline Electricity & 0.489 & $f_{\mathrm{CO}_{2}, \mathrm{el}}$ \\
Natural gas & 0.202 & $f_{\mathrm{CO}_{2}, \mathrm{ng}}$ \\
\hline
\end{tabular}

The $\mathrm{CO}_{2}$ emissions, $m_{\mathrm{CO}_{2}}$, for each scenario are calculated according to equation 12 .

$$
m_{\mathrm{CO}_{2}}=E_{\mathrm{ng}} \cdot f_{\mathrm{CO}_{2}, \mathrm{ng}}+\left(E_{\mathrm{el}}-E_{\mathrm{el}, \mathrm{CHP}}\right) \cdot f_{\mathrm{CO}_{2}, \mathrm{el}}
$$

\section{Net present value}

Fifths, we calculate the net present value. Therefore, we quantify the nominal investment cost as well as annual revenues and costs. The high-temperature network already exists, and thus, no investment is necessary for the high-temperature scenario. We calculate the initial investment $I_{0}$ for the low-temperature scenarios with equation 13 .

$$
I_{0}=I_{\mathrm{HP}}+I_{\text {Radiators }}+I_{\mathrm{AHU}}+I_{\text {Pipes }}
$$

The investment cost for heat pumps, $I_{\mathrm{HP}}$, radiators, $I_{\text {Radiators }}$, air handling units, $I_{\mathrm{AHU}}$ and pipes $I_{\text {Pipes }}$ is based on literature (Platt et al. (2010), Kampmann 
GmbH (2018), Goebel (2015), C.Dötsch et al. (1998)). We calculate the annual costs and revenues for the net present value analysis based on annual energy consumption. This energy consumption consists of electrical energy for pumping and heat pump operation and energy from natural gas for CHP and gas burner operation. We extract those values from the simulation results and scale them up to annual costs and revenues using the energy costs of Table 3.

\begin{tabular}{lc}
\multicolumn{2}{c}{ Table 3: Energy cost $[E U R / M W h]$} \\
\hline Energy & $c$ \\
\hline Electricity & 170.9 \\
Natural gas & 26.9 \\
\hline
\end{tabular}

The electricity cost, $c_{\mathrm{el}}$ and the natural gas cost, $c_{\mathrm{ng}}$ equal the average industrial cost of 2017 in Germany (Bundesverband der Energie-Abnehmer (2018) and Bundesnetzagentur Bundeskartellamt and (Keine Angabe) (2019)). The annual revenues, $R$, consist of the avoided cost due to savings of energy consumption in the remaining high-temperature network. We calculate $R$ according to equation 14 .

$$
R=E_{\mathrm{Pump}, \mathrm{HTDH}} \cdot c_{\mathrm{el}}+E_{\mathrm{ng}} \cdot c_{\mathrm{ng}}
$$

The annual costs, $C$, depend on additional electrical consumption for heat pump and pump operation and fewer electricity generation due to a reduced CHPoperation according to equation 15 .

$$
C=\left(E_{\mathrm{Pump}, \mathrm{LTDH}}+E_{\mathrm{HP}}+E_{\mathrm{el}, \mathrm{CHP}}\right) \cdot c_{\mathrm{el}}
$$

The net present value is calculated using equation 16 .

$$
N P V_{\mathrm{n}}=-I_{0}+\frac{(i+1)^{n}-1}{(i+1)^{n} \cdot i} \cdot(R-C)
$$

The interest rate, $i$, is set to $4 \%$ and the duration, $n$, equals 20 years. Additionally, the payback period, $t_{\text {payback}}$, is calculated with equation 17 .

$$
t_{\text {payback }}=-\frac{\ln \left(1-\frac{I_{0}}{R-C} \cdot i\right)}{\ln (1+i)}
$$

The payback period is the duration after which the initial investment is regained by repeating revenues.

\section{Results}

In this section, the results of the simulation are evaluated. First, we evaluate the pressure drop of the low-temperature scenarios. Second, we evaluate exergy, primary energy and $\mathrm{CO}_{2}$ emissions. Third, we evaluate the net present value.

\section{Pressure drop}

Figure 5 shows the maximum specific pressure drop for each simulated pipe for the $\mathrm{LTDH}_{\mathrm{HX}}$ simulation. Mainly pipes with diameter DN32 to DN100

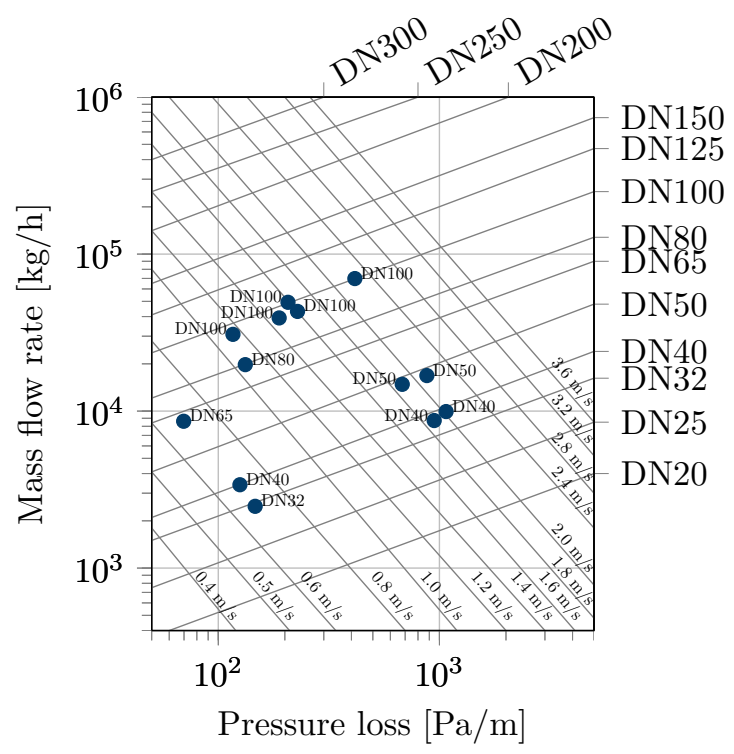

Figure 5: Pressure loss chart $\mathrm{LTDH}_{H X}$

are shown. Pipes with larger diameter tend to show lower pressure drops and are located outside of this pressure loss chart. The maximum pressure drop of the pipes in this chart during the simulation go up to $1000 \mathrm{~Pa} / \mathrm{m}$. This value is high compared to usual design values of $100 \mathrm{~Pa} / \mathrm{m}$ (C.Dötsch et al. (1998)). Figure 5 shows, that twelve pipes exceed the $100 \mathrm{~Pa} / \mathrm{m}$ threshold. Five of those twelve pipes show specific pressure losses larger than $400 \mathrm{~Pa} / \mathrm{m}$. The highest values are reached by pipes with diameter smaller or equal to DN50. Those pipes are usually used for building connections.

Figure 6 shows the pressure loss chart for pipes of the $\mathrm{LTDH}_{\mathrm{HP}}$ simulation. The maximal pressure drops

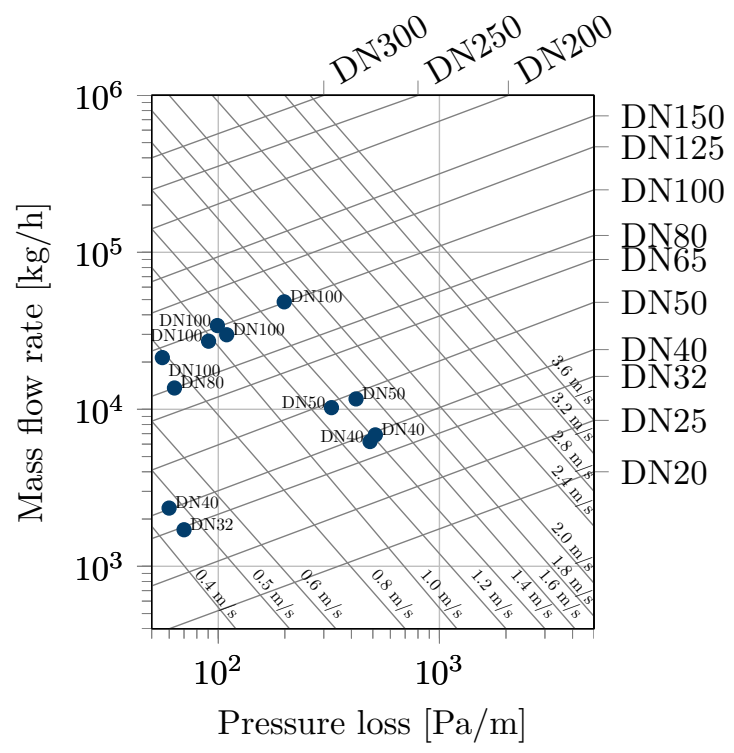

Figure 6: Pressure loss chart $L_{T D H} H_{H}$

in Figure 6 stay below $500 \mathrm{~Pa} / \mathrm{m}$ and no pipe shows higher flow velocities than $1.6 \mathrm{~m} / \mathrm{s}$. Additionally, only six pipes exceed the design threshold of $100 \mathrm{~Pa} / \mathrm{m}$. 
However, the same pipes with DN50 or smaller show high specific pressure losses up to $500 \mathrm{~Pa} / \mathrm{m}$. The high pressure losses occur because of the high mass flow rates in the low-temperature scenarios. The mass flow rate increases because of the smaller temperature spread of only $10 \mathrm{~K}$ compared to the larger $60 \mathrm{~K}$ of the high-temperature network. The mass flow rates decline when heat pumps substations are used.

In summary, the pressure drop charts show, that both low-temperature scenarios are technically feasible. Both scenarios will however result in high pressure losses in the network with multiple pipes exceeding design conditions. For the $\mathrm{LTDH}_{\mathrm{HP}}$ scenario, fewer pipes are outside of design conditions compared to the $\mathrm{LTDH}_{\mathrm{Hx}}$ scenario. Therefore, it is technically feasible to use existing pipes for the low temperature scenarios when only a few pipes are exchanged.

\section{Evaluation results}

Figure 7 shows the annual exergy consumption, annual primary energy consumption and annual $\mathrm{CO}_{2}$ emissions of the three scenarios.

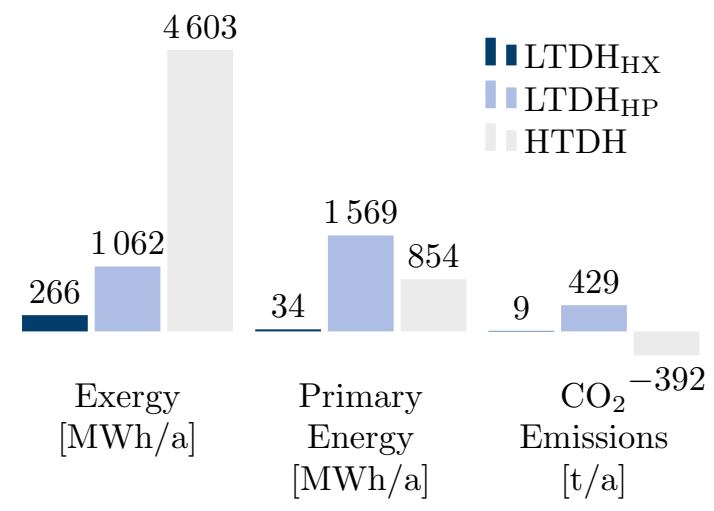

Figure 7: Evaluation results with CHP and gas burner operation in high-temperature supply

For exergy consumption, the $\mathrm{LTDH}_{\mathrm{HX}}$ scenario performs best, followed by the $\mathrm{LTDH}_{\mathrm{HP}}$ scenario and the HTDH scenario consumes the most exergy. The $\mathrm{LTDH}_{\mathrm{HX}}$ scenario has the lowest primary energy consumption. However, due to the feed-in of electrical energy during CHP operation, the HTDH scenario shows a lower primary energy consumption compared to $\mathrm{LTDH}_{\mathrm{HP}}$. For the $\mathrm{CO}_{2}$ emissions, this effect is even more significant. The HTDH scenario results in a negative $\mathrm{CO}_{2}$ balance, whereas $\mathrm{LTDH}_{\mathrm{HX}}$ has a small $\mathrm{CO}_{2}$ emission and the $\mathrm{LTDH}_{\mathrm{HP}}$ scenario shows the highest $\mathrm{CO}_{2}$ consumption. The good performance of the HTDH scenario is caused by the high share of CHP operation, which is replaced by the operation of the low temperature network. However, for the $\mathrm{HTDH}_{\text {new }}$ simulation the controller of the supply was not changed. Due to the decreased network size that the CHP has to supply, it can be possible to adapt the heating curve of the high temperature network. This can improve the performance of the low temperature network, because it would mainly replace gas burner operation.
The results of this best case scenario are shown in figure 8 .

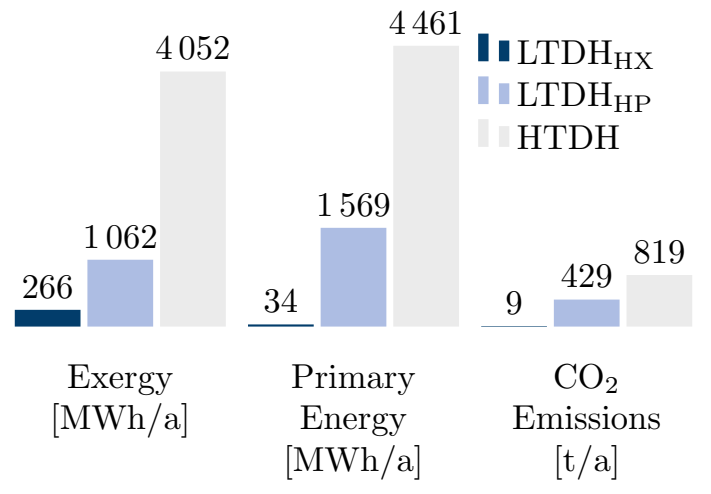

Figure 8: Evaluation results with only gas burner operation in high-temperature supply

Figure 8 show the best possible result for the waste heat integration. It evaluates the integration of waste heat against the gas burner operation. In this case, both low temperature scenarios show good results. The primary energy consumption is decreased significantly and the $\mathrm{CO}_{2}$ emissions are almost cut in half.

\section{Net present value}

The results of the primary energy consumption and $\mathrm{CO}_{2}$ emissions show a very good performance of the $\mathrm{LTDH}_{\text {direct }}$ scenario. However, retrofitting all buildings increases the total investment for the scenario which influences the economical evaluation. The total investment for both low-temperature scenarios is shown in Table 4.

Table 4: Investment cost in [1000 EUR]

\begin{tabular}{lcc}
\hline & LTDH $_{\mathrm{HX}}$ & LTDH $_{\mathrm{HP}}$ \\
\hline Pipes & 134 & 134 \\
Building energy system & 2116 & 0 \\
Heat pump & 0 & 215 \\
\hline \hline$\sum$ & 2250 & 349 \\
\hline
\end{tabular}

The investment for $\mathrm{LTDH}_{\mathrm{HX}}$ is more than six times higher than the investment of $\mathrm{LTDH}_{\mathrm{HP}}$. The high difference of investment cost is induced by the high retrofit cost of building energy systems compared to heat pump installation.

Table 5 shows the annual costs and revenues for both low-temperature scenarios.

Table 5: Annual costs and revenues in [1000 EUR]

\begin{tabular}{lcc}
\hline & $\mathrm{LTDH}_{\mathrm{HX}}$ & $\mathrm{LTDH}_{\mathrm{HP}}$ \\
\hline Cost & -3 & -149 \\
Revenues & 109 & 109 \\
\hline \hline$\sum$ & 106 & -40 \\
\hline
\end{tabular}

The annual cost for $\mathrm{LTDH}_{\mathrm{HP}}$ is significantly higher than for $\mathrm{LTDH}_{\mathrm{HX}}$, because of the heat pump opera- 
tion. Both low-temperature scenarios have an identical impact on the high-temperature network, and thus, identical annual revenues of $109000 \mathrm{EUR} / \mathrm{a}$.

Table 6 shows the results of the net present value analysis.

Table 6: Net present value results

\begin{tabular}{lcc}
\hline & LTDH $_{\mathrm{HX}}$ & $\mathrm{LTDH}_{\mathrm{HP}}$ \\
\hline $\mathrm{NPV}_{20}$ & $-808163 \mathrm{EUR}$ & $-854840 \mathrm{EUR}$ \\
$\mathrm{t}_{\text {payback }}$ & $48 \mathrm{a}$ & - \\
\hline
\end{tabular}

Both low temperature scenarios yield a negative NPV after 20 years. In addition, the $\mathrm{LTDH}_{\mathrm{HX}}$ scenario has a payback period of 48 years. This long paypack period is mainly driven by the high investment cost. The $\mathrm{LTDH}_{\mathrm{HP}}$ scenario has higher annual costs than revenues and thus, does not yield a payback period. For the $\mathrm{LTDH}_{\mathrm{HP}}$ scenario the difference between cost and revenues result of the high price difference between electricity and natural gas, according to table 3 .

\section{Discussion}

The network is simulated with a detailed pipe model and simple demand and supply models. The the equivalent length method for additional pressure losses due to components, bends and changes of diameters yields only a rough estimation of additional pressure drops. Furthermore, $\zeta$-values are common to describe pressure losses of components. Thus, a method to set a parameter for $\zeta$-values, for additional components in the pipe model can improve the model generation.

Due to the size of the high-temperature network, simple demand and consumer models are necessary to achieve reasonable simulation times. The $\mathrm{HTDH}_{\text {new }}$ simulation with 94 demand models takes $59400 \mathrm{~s}$, the $\mathrm{HTDH}_{\text {ref }}$ scenario with 104 demand models takes $86400 \mathrm{~s}$. We simulate all models on an openSUSE 42.3 system with Intel Core i7-7700 CPU and 32 GB RAM. However, for small-scale simulations, like the low-temperature network, more detailed consumer and demand models are possible. For further work, linking the automated model generation with more detailed models offers the potential to evaluate e.g. part load behavior, thermal energy storages and additional retrofit possibilities.

The simulation results show that the integration of waste heat is technically feasible in this scenario, when certain critical pipes are exchanged. Most of those pipes are connections to buildings and not larger distribution pipes. It is only possible to decrease primary energy consumption and $\mathrm{CO}_{2}$ emissions with the integration of waste heat, when the CHP-operation of the high-temperature network is not decreased. In this case the low temperature network reduces the operation of the additional gas burner. To achieve this goal, the control algorithms for both networks need to be optimized. For the high temperature network for example, the flow temperature should remain beneath the maximum CHP heating temperature of $115^{\circ} \mathrm{C}$ to minimize operation hours of the auxiliary gas burner. Waste heat integration for the low-temperature network helps achieving this goal by decreasing the thermal power demand of the remaining high-temperature network. Both low temperature scenarios do not operate economically with the given settings. The performance depends on the energy efficiency ratio (EER) of the low temperature network, the electrical energy consumption and the prices for electricity and natural gas. The minimal EER to gain higher revenues than costs depends on the ratio between $c_{e l}$ and $c_{n g}$. With the costs of table 3 the minimal EER to achieve positive annual cash flow is 5.72. For the $\mathrm{LTDH}_{\mathrm{HX}}$ scenario, the EER is 200 and the $\mathrm{LTDH}_{\mathrm{HP}}$ yields an EER of 3.4. The demands in the $\mathrm{LTDH}_{\mathrm{HP}}$ scenario operate with constant flow temperatures. The EER of the $\mathrm{LTDH}_{\mathrm{HP}}$ scenario can be improved by applying a heating curve to the demand substation, which is state of the art for existing building energy systems.

\section{Conclusion}

The evaluation of the simulation stresses, that using waste heat instead of high-temperature district heating can be ecologically worthwhile. Due to the electricity generation of the CHP plant, the CHP operation should not be reduced by the low-temperature network. Therefore, the low-temperature network needs to maximize its operation during high load times, where the gas burner of the high-temperature network operates. The ecological results improve by retrofitting the buildings and allowing the building energy system to use waste heat directly. This decreases the primary energy consumption and $\mathrm{CO}_{2}$ emissions significantly. Both low-temperature scenarios result in a worse economical evaluation compared to gas burner supply. Measures to improve this performance are e.g. control optimization.

The simulation models are a good basis for future work to optimize those controls. The tool for automated generation of dynamic simulation models from a citygml database is useful to adapt the simulation models accordingly. Therefore, more detailed demand and supply models need to be available for the model generation.

In conclusion, this work shows that the planned integration of waste heat into an existing district heating network is technically feasible and yields a good ecological result. However, the simulation results show, that this integration is economically worse than the high-temperature supply. A more detailed simulation can offer the potential to evaluate retrofit measures of single building energy system, as well as more detailed results of the whole district heating network. A sensitivity analysis for the energy costs can give more in- 
sight into the economical feasibility of waste heat integration. Additionally, packages like TEASER (Remmen et al. (2018)) can help to evaluate retrofit measures. For future work, the combination of the simulation framework with an evaluation of retrofit measures is planned.

\section{Acknowledgements}

We gratefully acknowledge the financial support by BMWi (German Federal Ministry of Economic Affairs and Energy), promotional reference 03EGB0010A.

\section{References}

Bundesnetzagentur Bundeskartellamt and (Keine Angabe) (2019). Gaspreise für Gewerbe- und Industriekunden in Deutschland in den Jahren 2008 bis 2018 (in Euro-Cent pro Kilowattstunde). https://de.statista.com/statistik/daten/ studie/168528/umfrage/gaspreise-fuergewerbe--und-industriekunden-seit-2006/.

Bundesverband der Energie-Abnehmer (2018).

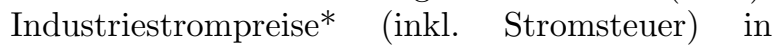
Deutschland in den Jahren 1998 bis 2018 (in Euro-Cent pro Kilowattstunde). https: //de.statista.com/statistik/daten/studie/ 252029/umfrage/industriestrompreise-inklstromsteuer-in-deutschland/.

C.Dötsch, J.Taschenberger, and I.Schönberg (1998). Leitfaden Nahwärme.

Coker, A. K. and E. E. Ludwig (2007). Ludwig's applied process design for chemical and petrochemical plants: Volume 1 (4th ed. ed.). Amsterdam and Boston: Elsevier Gulf Professional.

Der Energieeffizienzverband für Wärme, Kälte und KWK e.V. (2014). Arbeitsblatt AGFW FW 309 Teil 1: Energetische Bewertung von Fernwärme.

Fuchs, M., J. Teichmann, M. Lauster, P. Remmen, R. Streblow, and D. Müller (2016). Workflow automation for combined modeling of buildings and district energy systems. Energy 117, 478-484.

Goebel, C. (2015). Wirtschaftlichkeitsbetrachtung gebäude- und netzseitiger Energieeinsparmaßnahmen für die Wärmeversorgung des Forschungszentrums Jülich.

Kampmann GmbH (2018). Klima-, Lüftungs- und Kälteanlagen von Kampmann. https://www. kampmann.de/produkte/.

Koomey, J. G. (2011). Growth in data center electricity use 2005 to 2010 .

Lund, H., S. Werner, R. Wiltshire, S. Svendsen, J. E. Thorsen, F. Hvelplund, and B. V. Mathiesen (2014). 4th Generation District Heating (4GDH). Energy 68, 1-11.
Müller, D., M. Lauster, A. Constantin, M. Fuchs, and P. Remmen (2016). AixLib - An Open-Source Modelica Library Within The IEA - EBC Annex 60 Framework. In J. Grunewald (Ed), Proceedings of the CESBP Central European Symposium on Building Physics and BauSIM 2016, pp. 3-9. Stuttgart: Fraunhofer IRB Verlag.

Platt, M., S. Exner, and R. Bracke (2010). Analyse des deutschen Wärmepumpenmarktes: Bestandsaufnahme und Trends.

Remmen, P., M. Lauster, M. Mans, M. Fuchs, T. Osterhage, and D. Müller (2018). TEASER: an open tool for urban energy modelling of building stocks. Journal of Building Performance Simulation 11(1), 84-98.

Umweltbundesamt (2017). Entwicklung des Endenergieverbrauchs der privaten Haushalte. https://www. umweltbundesamt.de/sites/ default/files/medien/384/bilder/dateien/ 2_abb_entwicklung-eev-ph_2018-02-23.pdf.

Umweltbundesamt (2018a). Endenergieverbrauch nach Anwendungsbereichen 2016: Private Haushalte. https://www. umweltbundesamt.de/sites/default/files/ medien/384/bilder/dateien/3_abb_eev-nachanwendungsbereichen-ph_2018-02-23.pdf.

Umweltbundesamt (2018b). Strom- und Wärmeversorgung in Zahlen. https: //www . umweltbundesamt. de/themen/klimaenergie/energieversorgung/stromwaermeversorgung-in-zahlen.

van der Heijde, B., M. Fuchs, C. Ribas Tugores, G. Schweiger, K. Sartor, D. Basciotti, D. Müller, C. Nytsch-Geusen, M. Wetter, and L. Helsen (2017). Dynamic equation-based thermo-hydraulic pipe model for district heating and cooling systems. Energy Conversion and Management 151, 158-169.

Wahlroos, M., M. Pärssinen, J. Manner, and S. Syri (2017). Utilizing data center waste heat in district heating - Impacts on energy efficiency and prospects for low-temperature district heating networks. Energy 140, 1228-1238. 